\title{
A IGREJA DE SANTA CECÍLIA: AS PINTURAS DE BENEDITO CALIXTO E DE OSCAR PEREIRA DA SILVA NA CONFLUÊNCIA DOS INTERESSES DA IGREJA CATÓLICA E DA ELITE CAFEEIRA, EM SÃO PAULO, NO INÍCIO DO SÉCULO XX
}

Cristina de Toledo Romano - USP

\section{Resumo:}

O conjunto de obras de Benedito Calixto e de Oscar Pereira da Silva que integram o interior da Igreja de Santa Cecília, realizadas entre as duas primeiras décadas do século XX, compõe diferentes histórias e perfaz narrativas que se expõem de forma similar, encontrandose no cruzamento de expectativas e de interesses da camada privilegiada da sociedade paulista, na época responsável pela exploração cafeeira, e da Igreja Católica que, nesta ocasião, empreende uma reforma em seu interior, buscando legitimar-se no contexto republicano.

Palavras-chave: pintura sacra, Benedito Calixto, Igreja de Santa Cecília.

\begin{abstract}
:
The Benedito Calixto's and the Oscar Pereira da Silva's pictures in the St Cecília's church realized between the two first decades of the 20th century in São Paulo, constitutes diferent histories and completes narratives which expose themselves with a similar form. Those histories are in the crossing of the privileged class's interestes and of the Catolic Church's expectation that in this period undertakes a reform purposing conquer legitimacy in the republican context.
\end{abstract}

Key words: sacre painting, Benedito Calixto, St Cecília's church

O conjunto de imagens que integram o interior da igreja de Santa Cecília na cidade de São Paulo inclui pinturas de Benedito Calixto e de Oscar Pereira da Silva realizadas entre 1909 e 1917. A análise dessas obras permite afirmar que a realização das mesmas atendia aos interesses e necessidades da Igreja Católica na época, bem como aos do grupo abastado, diretamente vinculado à exploração e comercialização do café e ligado à então Paróquia de Santa Cecília. ${ }^{1}$

Benedito Calixto é responsável quase que pela totalidade das pinturas: são de sua autoria os seis painéis representando a história de Santa Cecília e os onze retratos dos primeiros papas na capela-mor; os dois painéis referentes à história paulista sobre os tímpanos das duas capelas laterais à capela-mor; os doze retratos de todos os bispos da Diocese de São Paulo até aquela época, nos nichos que guarnecem o friso do entablamento das capelas laterais; e os dezesseis painéis sobre os nichos que guarnecem o friso e o entablamento da nave central, representando os primeiros mártires cristãos e arcanjos.

\footnotetext{
${ }^{1}$ A Paróquia criada em 1895 conta, desde os primórdios, com a colaboração financeira de famílias abastadas da capital paulista, que direta ou indiretamente estavam ligadas à exploração cafeeira e à política local, e que foram contribuintes para a construção e decoração da igreja. De acordo com as análises até então realizadas, as principais famílias contribuintes da paróquia eram: Arruda Alvim, Barros, Carvalho, Carmo Cintra, Monteiro de Barros, Mendonça, Prado, Prates, Souza Queiroz, entre outras.
} 
Oscar Pereira da Silva pintou os painéis retratando a Imaculada Conceição e Os Esponsais de São José nas capelas do transepto.

As duas histórias representadas por Benedito Calixto, a de Santa Cecília e a de São Paulo desenvolvem-se em torno de narrativas. A história de Santa Cecília se inicia com o batismo de Valeriano, esposo de Cecília, abordando na seqüência o episódio que consagra a conservação da virgindade de Cecília e de Valeriano; o batismo dos algozes de Valeriano e de seu irmão Tibúrcio; o interrogatório; e o martírio de Cecília e por fim, a cerimônia de sepultamento de Cecília.

A narrativa sobre a história paulista aborda dois momentos da vida de Pero Corrêa, um traficante de índios que, no período colonial, atuava, principalmente, junto à aldeia de Itanhaém, e que posteriormente veio a se converter em membro da Companhia de Jesus. ${ }^{2} \mathrm{Um}$ dos painéis referentes a essa história representa a situação em que o padre Leonardo Nunes, suposto responsável pela conversão de Corrêa, interdita uma de suas ações como apresador. O outro representa o momento de seu assassinato pelos índios carijós, em uma missão na região de Cananéia.

As duas histórias representadas por Calixto são expostas de forma semelhante: ambas são acompanhadas por elementos da Igreja Católica. Acima do limite superior de cada uma das telas sobre Santa Cecília estão colocados três pequenos retratos de papas, enquanto que, seguindo o mesmo padrão estético, portanto, acima dos painéis sobre Pero Corrêa, encontram-se, da mesma maneira, os retratos dos bispos de São Paulo.

A similaridade quanto à exposição dessas duas narrativas sugere uma equiparação entre elas, ou seja, sugere que a história de Santa Cecília tanto quanto a de Pero Corrêa gozam da mesma importância, o que justifica o fato de terem sido apresentadas de forma semelhante. Assim, o martírio do bandeirante convertido em São Paulo, no século XVI, ganha o mesmo significado que o da santa, ocorrido nos primórdios da era cristã, em Roma.

A representação da figura do bandeirante tornou-se corrente em São Paulo entre o final do século XIX e o começo do século XX, não apenas no contexto da produção pictórica, mas também no da produção literária. Nesta época, recuperou-se uma imagem do bandeirante cunhada no século XVIII por representantes dos setores privilegiados da sociedade colonial, motivados pela necessidade de defender os antigos habitantes da cidade de São Paulo contra os recém-chegados da região das Minas. A insegurança gerada por esse movimento teria levado, de acordo com Kátia Abud, à atribuição das qualidades de bravura e superioridade aos paulistas, através da criação de uma imagem extremamente positiva de seus antepassados, que deveriam ser lembrados como aqueles que haviam conquistado índios, territórios e descoberto as minas de ouro.

A retomada desse mito, no século XIX, serviu para a legitimação dos paulistas no comando da nação, a partir da proclamação da república. Este esforço foi empreendido por seus representantes intelectuais que buscaram embasar seus trabalhos em fontes documentais

\footnotetext{
2 Cf. CALIXTO, Benedito. A Vila de Itanhaém, segunda povoação fundada por Martim Afonso de Souza: estudos históricos sobre sua fundação, seu desenvolvimento, sua decadência e estado atual. Santos: Diário de Santos, 1985, pp. 426-429.
} 
concretas. Os argumentos utilizados, anteriormente, foram, novamente evocados. ${ }^{3}$ Os bandeirantes continuaram sendo considerados superiores moralmente e racionalmente.

Contudo, passou-se a evidenciar mais firmemente o aspecto de desbravador e de condutor do progresso, na perspectiva de se enfatizar, inclusive, a responsabilidade da economia cafeeira para a continuidade deste progresso.

A representação do bandeirante na igreja de Santa Cecília leva à sacralização do mesmo, e conseqüentemente de um momento da história de São Paulo, contribuindo, portanto, com aquele discurso exaltador.

É importante observar, no entanto, que a representação trata de glorificar um tipo especial de bandeirante. Pero Corrêa é um bandeirante que se curvou à ação jesuítica. A cena que retrata o momento em que Pero Corrêa e seu companheiro são surpreendidos pelo padre Leonardo Nunes expõe claramente o contraste entre a prática religiosa e a apresadora. A atitude convicta do jesuíta em face do bandeirante se expressa através de sua postura hirta, de seu movimento preciso, ostentando o braço direito esticado em sinal de interdição e um olhar rigidamente direcionado àquele. Contrariamente à exposição do corpo de Leonardo Nunes, o de Pero Corrêa se posta com menos segurança: os ombros caídos, a cabeça abaixada e os braços cruzados denotam a incerteza e a fragilidade de sua prática quando confrontada com a do outro.

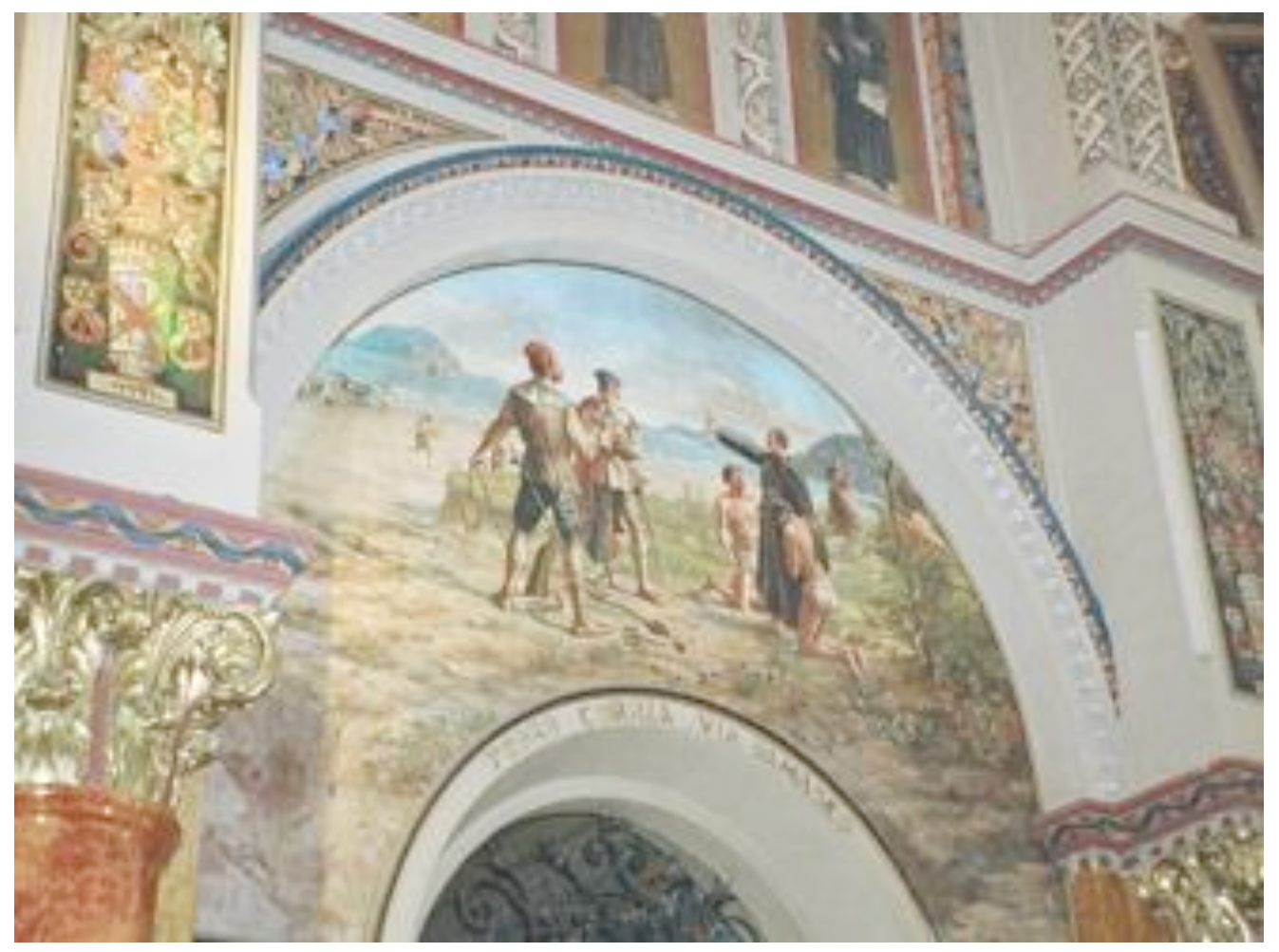

\footnotetext{
${ }^{3}$ Cf. Abud, Kátia Maria. “A idéia de São Paulo como formador do Brasil”. DE LUCA, Tânia Regina; FERREIRA, Antonio Celso; IOKOI, Zilda Grícoli (orgs.). Encontros com a história: percursos históricos e historiográficos de São Paulo. São Paulo: Editora da UNESP, 1999.
} 
O painel que se segue a este, cuja temática é o assassinato de Pero Corrêa pelos carijós, enaltece a figura do bandeirante tornado jesuíta. Vítima da atrocidade do índio que é flagrado no ato do crime o ex-bandeirante se apresenta convicto de sua opção religiosa, pois está ajoelhado, dirigindo seu olhar piedoso e sereno aos céus em atitude de contemplação, no momento exato de sua morte.

A pertinência deste tipo de representação, evidenciando a importância da religião no começo do século XX, associa-se à nova situação da Igreja Católica no contexto republicano ${ }^{4}$ e ao desenvolvimento de práticas voltadas para a aplicação de orientações reformistas no âmbito da instituição. Tais orientações que visavam a reestruturação da Igreja inserem-se numa ação mais ampla empreendida pela Igreja Católica em escala mundial, que se inicia com o pontificado de Pio IX, em 1846, e se estende até a Primeira Guerra. Modelos de organização eclesiástica, de crenças e de práticas religiosas foram fornecidos pela Santa Sé e aplicados pelos bispos do Brasil.

Em São Paulo, o processo de "romanização" da Igreja inicia-se com o bispo Dom Antonio Joaquim de Melo (1851-1861) que, entre outras medidas, procurou controlar e dominar as associações religiosas dirigidas por leigos até aquela época, na perspectiva de limitar a propagação dos princípios e das práticas católicas populares. ${ }^{5}$ cristãos. $^{6}$

Assim, a Igreja buscava sua legitimação enquanto detentora absoluta dos preceitos

Apesar da análise da série de imagens realizadas por Benedito Calixto acerca da vida de Santa Cecília estar ainda em fase inicial, é possível observar que seu conjunto também evidencia a importância da Igreja enquanto instituição responsável pela oferta dos sacramentos. Dos seis painéis que integram esta série de imagens, três abordam cerimônias direcionadas pela instituição eclesiástica: a que abre a narrativa, representando o batismo de Valeriano; o que representa o batismo dos responsáveis pelo martírio de Valeriano e de seu irmão; e o que fecha a narrativa, representando o sepultamento de Cecília. Nas três imagens, ocorre a incidência de uma luz sobre os atos realizados pelo bispo Santo Urbano. No último painel, o clérigo ocupa o centro da cena; sobre ele incide a luz que advém dos céus. O translado de Cecília para o suposto plano superior é, portanto, intermediado pela Igreja, já que é o padre que se interpõe entre a falecida e o universo sagrado. É ele o grande abençoado.

De fato, a análise de outra documentação referente à paróquia de Santa Cecília demonstra o esforço de seu vigário para legitimar a Igreja enquanto administradora das práticas sacramentais. Trata-se de um jornal escrito por ele e dirigido aos paroquianos, do qual se extrai, entre outros, avisos e chamamentos como o que se segue:

A Igreja, recebendo do Salvador os Santos Sacramentos, recebeu com eles o poder de administrá-los e de legislar sobre tudo a que eles se referem. Vendo, pois, que

\footnotetext{
${ }^{4}$ É importante lembrar a separação ocorrida entre a Igreja e o Estado, consolidada na Constituição de 1891. A partir deste período, a Igreja teve que empreender ações que a reposicionasse política e economicamente na nova ordem.

${ }^{5}$ Estas considerações acerca do processo de imposição do catolicismo reformador em São Paulo baseia-se nas análises de A. Wernet sobre o assunto. Ver em: WERNET, Augustin. A Igreja paulista no século XIX - A reforma de Dom Antonio Joaquim de Melo (1851-1861). São Paulo: Ática, 1987.

6 Cabe apontar que tal processo de legitimação, sobretudo junto às classes populares, esbarrou em muitas dificuldades, uma vez que, ao longo dos períodos colonial e imperial, o catolicismo propagado pela Igreja concorreu fortemente com o catolicismo de práticas populares.
} 
sem uma lei positiva que regulasse a recepção dos Sacramentos da Confissão e da Comunhão, facilmente se descuidavam os fiéis do cumprimento deste preceito, ordenou terminantemente que todos os fiéis se confessassem, ao menos uma vez por ano. Assim, pois, o preceito da Confissão só é eclesiástico em quanto ao tempo; em tudo o mais é puramente divino. Custa a crer que haja ainda católicos que, admitindo a instituição divina da Confissão, que, não querendo absolutamente morrer sem sacramentos, deixem tão facilmente de desobrigar-se, como se isto fora apenas um conselho, e não uma obrigação terminante e inadiável. ${ }^{7}$

Revelam-se, assim, as dificuldades para a imposição do cumprimento da prática sacramental; o que também demonstra a dificuldade em reconhecer-se a importância da Igreja enquanto promotora do conjunto das instituições "divinas". O padre deixa entrever um descontentamento quanto à falta de seriedade para com as leis eclesiásticas que regem os sacramentos, e repudia o reconhecimento da Igreja como mera conselheira.

A este propósito podem ser citadas, também, as interpelações do pároco quanto às negligências em face da dispensa do jejum e da abstinência, instituídos para a comemoração do nascimento de Cristo. De acordo com ele, a dispensa "tem como condição essencial o pedido feito a um sacerdote devidamente autorizado" e as pessoas que

por má vontade violam este preceito da Igreja, pecam tanto mais gravemente, quanto mais fácil é a dispensa, e é verdadeiramente inexplicável o descuido com que muitos se arriscam a ocasiões de pecado. ${ }^{8}$

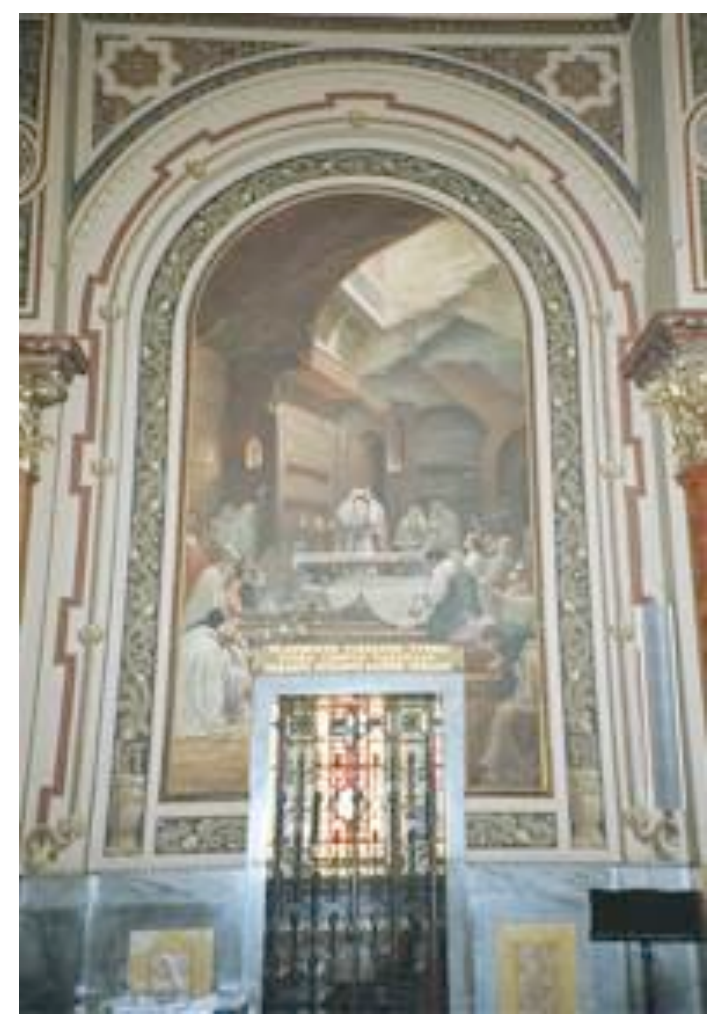

7 O Mensageiro Paroquial, 1 de março de 1901.

8 O Mensageiro Paroquial, 7 de dezembro de 1900. 
Deste modo, é lícito reconhecer que as pinturas na igreja de Santa Cecília fazem parte, sobretudo, do projeto que visava consolidar o domínio da instituição católica no começo do século XX sobre as práticas religiosas concernente ao credo em questão. Apesar da concessão feita à figura do bandeirante, que na época, atendia à necessidade das classes abastadas em cunhar uma ancestralidade valorosa para justificar a dominação exercida em seu presente, a Igreja buscou fixar no interior desse templo, senão a superioridade de sua causa em face daquela "desbravadora", pelo menos a necessidade e a importância da aliança entre ambas. 